\title{
ФОРМИРОВАНИЕ ГОСУСЛУГИ ПО СОПРОВОЖДЕНИЮ СОЗДАНИЯ И ФУНКЦИОНИРОВАНИЮ ПРЕДПРИЯТИЙ МАЛОГО БИЗНЕСА В МФЦ
}

\author{
М. М. Филатова, О. Ю. Романова \\ Московский гуманитарный университет
}

Аннотация: В статье обсуждается идея создания «МФЦ для бизнеса», который позволит эффективно развивать города, оказывать всестороннюю поддержку субъектам малого и среднего предпринимательства.

Текст доклада авторов на XV Международной научной конференции «Высшее образование для XXI века. Роль гуманитарного образования в контексте технологических и социокультурных изменений», которая прошла 14-16 ноября 2019 года в Московском гуманитарном университете.

Ключевые слова: многофункциональный центр; государственные услуги; малый бизнес; средний бизнес

\section{ESTABLISHING THE SERVICE OF SUPPORT FOR THE CREATION AND PERFORMANCE OF SMALL BUSINESSES AT MFC}

\author{
M. M. Filatova, O. Yu. Romanova \\ Moscow University for the Humanities
}

\begin{abstract}
The paper discusses the idea of establishing "Multifunctional Centres for Business", which will allow for efficient urban development and lend small and mediumsized businesses full support.

The text of the author's speech at the 15th International Scientific Conference "Higher Education for the 21st Century. The Role of Education in Humanities in the Contest of Technological and Sociocultural Changes" held at Moscow University for the Humanities on 14-16 November 2019.
\end{abstract}

Keywords: multifunctional centre; public services; small business; medium-sized business

В настоящее время малый и средний бизнес в России все больше интересует власти. Поддержка субъектов малого и среднего предпринимательства (МСП) способно значительно увеличить в объеме сферы приложения труда, сформировать новые рабочие места, помогать в развитии инфраструктуры и улучшении сферы услуг, что приобретает высокую степени актуальности в связи со специфичностью функционирования и развития городов. Малый и средний бизнес обеспечивает поддержание конкурентной среды, помогает населению моногородов в улучшении сферы бытового обслуживания, а также помогает товарами и услугами; реализует социаль- 
ные функции, формируя новые рабочие места для работников, не занятых на градообразующем предприятии или тех, которые высвобождаются в результате реорганизации и ликвидации градообразующих предприятий, способствует росту налоговых доходов муниципальных образований. Следует заметить, что для моногородов характерна низкая предпринимательская активность населения. По данным опроса ВЦИОМ в 2018 году 60\% россиян не желают становиться бизнесменами. Причинами могут быть как недостаточный уровень поддержки государственными и муниципальными органами власти, так и характерные особенности моногородов - ограниченный рынок сбыта продукции товаров и услуг, узость профессиональной структуры населения, также значительное воздействие могут оказывать «северные» факторы (Воронина, 2014). В свою очередь, рассчитывать только на материальную федеральную помощь в решении проблем моногородов и финансовую поддержку малого предпринимательства не совсем правильный подход, необходимо создавать условия для развития малого бизнеса в моногородах, минимизировать бюрократизм при поддержке МСП, разрабатывать систему ключевых показателей эффективности (Борисенко, 2013).

Тем не менее, нежелание малого бизнеса кредитоваться появляется, в частности, от недостаточной информированности, избыточной осторожности. В свою очередь, малый бизнес может развиваться, подниматься на новый уровень, но для расширения всегда необходимы немалые финансовые вливания. Так что, заинтересованность МСП в кредитах будет существовать. Малый бизнес зависит от потребительской конъюнктуры, поэтому в условиях, когда потребители имеют стремление сэкономить, бизнесу также приходится придерживаться данной тактики. Цикличность спадов и подъемов экономики обуславливает развернутую кампанию в поддержку малого бизнеса. Отсутствие интеграциии координации ресурсов и информации, понимание показателей (Васильева, 2005) ведет к снижению эффективности проводимых мероприятий по поддержке малого и среднего бизнеса.

В 2015 г. появился новый инструмент - Корпорация развития МСП. Учреждение оказывает поддержку субъектам МСП и предлагает гарантийный механизм, который уже позволил предоставить субъектам МСП более 89 миллиардов рублей. А также программу стимулирования кредитования субъектов МСП «Программа 6,5», которая предусматривает ставку для субъектов малого предпринимательства - 10,6\% и 9,6\% для субъектов среднего бизнеса. Также Корпорацией проводятся обучающие программы начинающим Бизнесменам (программа «Азбука предпринимателя»). В программе «Школа бизнеса» для предпринимателей делается ставка на анализ и оптимизацию реального бизнеса. 
Ряд услуг Корпорации МСП предприниматели могут получить через многофункциональные центры предоставления государственных и муниципальных услуг (далее - МФЦ). К таким услугам относится предоставление данных о недвижимом имуществе, которые помогут найти подходящее помещения для ведения и реализации бизнеса. Также МФЦ предоставляет информацию о закупках, планируемых крупными заказчиками, и сведения о формах и условиях финансовой поддержки субъектов МСП.

Свежей инициативой по избавлению предпринимателей от контактов с бюрократическими аспектами взаимодействия с органами власти является реализация федерального проекта «МФЦ для бизнеса», в рамках которого к 2019 г. в России предполагается создание специализированной системы «одного окна» для обслуживания юридических лиц и индивидуальных предпринимателей на базе МФЦ в городах с населением более 100 тыс. человек, а также в моногородах, целью которого является предоставление услуг малому и среднему бизнесу без лишних бюрократических барьеров, в том числе услуг, необходимых для начала и ведения предпринимательской деятельности. Согласно проведенному исследованию удовлетворенности граждан РФ качеством предоставления государственных и муниципальных услуг в 2016 г., показатель «Среднее количество обращений представителей бизнес-сообщества» составил 1,97 при плановом значении 2, что означает актуальность развития и совершенствования партнерства государства и бизнеса на базе МФЦ.

«МФЦ для бизнеса» объединят услуги, которые необходимы для развития бизнеса - государственные услуги; услуги, оказываемые Корпорацией МСП и другими институтами развития.

В этом ключе услуги могут быть разбиты на бизнес-ситуации, к примеру, «Открытие своего дела», «Перевозка пассажиров и грузов» и т. д., в соответствии с которыми МФЦ оказывают поддержку предпринимателям, а также организациям, находящимся на различных этапах «жизненного» цикла:

- бизнес - планирование (услуги по оказанию консультационной и информационной поддержки, в том числе помощь по составлению бизнес-планов и правоустанавливающих документов);

- регистрация и постановка на учет (подготовка и прием документов для регистрации ИП и ЮЛ, постановку на учет в ФНС, ПФР, ФСС и т. д.);

- финансирование (предоставление информации о формах и условиях финансовой поддержки субъектов МСП);

- уточнение требований органов власти, выдача разрешений, предоставление различной информации и выписок согласно соглашениям о 
взаимодействии, лицензирование отдельных видов предпринимательской деятельности, к примеру, выдача лицензий на розничную продажу алкогольной продукции и др.;

- размещение - подбор помещений и земельных участков (предоставление земельных участков, представление сведений, содержащихся в государственном кадастре недвижимости, в ЕГРП);

- персонал (информирование о положении на рынке труда в субъекте РФ, содействие гражданам в поиске подходящей работы, а работодателям - в подборе необходимых работников, консультирование об организации содействия самозанятости безработных граждан и др.;

- организация сбытовой инфраструктуры, формирование клиентской базы (предоставление информации об организации участия субъектов МСП в закупках товаров и работ);

- а также другие дополнительные сервисные услуги (маркетинговые, рекламные услуги, услуги по страхованию имущества, открытие расчетного счета, изготовление печатей и штампов и пр.).

Таким образом, проект «МФЦ для бизнеса» формирует систему информационной и консультационной поддержки и популяризации предпринимательской деятельности на базе учреждения, путем включения в перечень услуг, предоставляемых на базе МФЦ, связанныхс разрешительными процедурами в предпринимательской деятельности, а также в сфере поддержки субъектов малого и среднего предпринимательства. Для реализации единой информационно-коммуникационная системы «МФЦ для бизнеса»необходимо сформировать комплекс организационных, информационных и нормативно-методических мероприятий, к примеру, необходимо разработать типовые формы предоставления информации о поставщиках и их услугах для предпринимателей, регламентировать деятельность специалистов МФЦ по информационно-консультационному сопровождению МСП, определить перечень наиболее актуальных «бизнес-ситуаций» и т. д. (Турков, 2012).

Система комплексного сопровождения МСП, сформированная на базе МФЦ, позволит сформировать деловой климат в моногородах, обеспечивающий рост количества субъектов малого бизнеса и расширение спектра их товаров и услуг, даст возможность малому бизнесу найти ресурсы для роста своих предприятий.

Таким образом, цель «МФЦ для бизнеса» - дать возможность субъектам малого и среднего предпринимательства получить комплекс качественных услуг, необходимых для ведения бизнеса, максимально сократить время при их получении. Новая концепция государственно-частного взаимодействия позволит минимизировать бюрократические и администра- 
тивные барьеры при поддержке МСП, благоприятная среда и оказываемая поддержка должны стать фактором, который увеличит количество субъектов МСП в моногородах, приведет к росту налоговых поступлений в муниципальный бюджет и позволит снизить риски социально-экономического развития моногородов.

\section{СПИСОК ЛИТЕРАТУРЫ}

Борисенко, В. П. (2013) Методология контроля в процессе стратегического аудита // Контроллинг. №1 (47). С. 60-70.

Воронина, Л. В. (2014) Типология факторов, влияющих на предпринимательскую активность населения северных моногородов // Наука и образование: хозяйство и экономика; предпринимательство; право и управление. № 10. С. 18.

Турков, А. В. (2012) Развитие монопрофильных населенных пунктов в Российской Федерации: сборник научных трудов. М. : Финансовый университет.

Дата поступления: 10.11.2019 г.

Филатова Мария Михайловна - студентка магистратуры по направлению «Государственное муниципальное управление» Московского гуманитарного университета. Адрес: 111395, Россия, г. Москва, ул. Юности, д. 5. Тел.: +7 (916) 258-63-61. Эл.адрес: igoninamary@mail.ru

Романова Ольга Юрьевна - студентка магистратуры по направлению «Государственное муниципальное управление» Московского гуманитарного университета. Адрес: 111395, Россия, г. Москва, ул. Юности, д. 5.Тел.: +7 (962) 951-68-38. Эл. адрес: olga199480@mail.ru

Filatova Mariya Mikhaylovna, Graduate Student, academic programme "State Municipal Administration", Moscow University for the Humanities. Postal address: 5, Yunosti St., Moscow, Russian Federation, 111395. Tel.: +7 (916) 25863-61. E-mail: igoninamary@mail.ru

Romanova Olga Yuryevna, Graduate Student, academic programme "State Municipal Administration", Moscow University for the Humanities. Postal address: 5, Yunosti St., Moscow, Russian Federation, 111395. Tel.: +7 (962) 951-68-38. E-mail: olga199480@mail.ru 


\section{Для цитирования:}

Филатова М. М., Романова О. Ю. Формирование госуслуги по сопровождению создания и функционированию предприятий малого бизнеса в МФЦ [Электронный ресурс] // Научные труды Московского гуманитарного университета. 2020. № 1. URL: http:// journals.mosgu.ru/trudy/article/view/1125 (дата обращения: дд.мм.гг.). DOI: 10.17805/ trudy.2020.1.6 